\title{
ALIENAÇÃO FIDUCIÁRIA DE BENS IMÓVEIS EM GARANTIA AOS CONTRATOS EMPRESARIAIS
}

\author{
Dissertação de Mestrado
}

Orientador: Professor Dr. Francisco Paulo De Crescenzo Marino

UNIVERSIDADE DE SÃO PAULO

FACULDADE DE DIREITO

São Paulo-SP

2019 


\section{ALIENAÇÃO FIDUCIÁRIA DE BENS IMÓVEIS EM GARANTIA AOS CONTRATOS EMPRESARIAIS}

Dissertação apresentada à Banca Examinadora do Programa de Pós-Graduação em Direito, da Faculdade de Direito da Universidade de São Paulo, como exigência parcial para obtenção de título de Mestre em Direito, na área de concentração Direito Civil, sob a orientação do Professor Dr. Francisco Paulo De Crescenzo Marino.

UNIVERSIDADE DE SÃO PAULO

FACULDADE DE DIREITO

São Paulo-SP

2019 
Autorizo a reprodução e divulgação deste trabalho, por qualquer meio convencional ou eletrônico, para fins de estudo e pesquisa, desde que citada a fonte.

\section{Catalogação da Publicação}

Faculdade de Direito da Universidade de São Paulo

Benedetti, Andressa.

Alienação fiduciária de bens imóveis em garantia aos contratos empresariais / Andressa Benedetti;

Orientador: Francisco Paulo De Crescenzo Marino. - São Paulo, 2019. 165 fls.

Dissertação (Mestrado) -- Universidade de São Paulo, 2019.

Introdução. 1. O negócio fiduciário. 2. As garantias reais. 3. A alienação fiduciária de bens imóveis. 4. A satisfação do crédito. 5. As adequações necessárias aos contratos empresariais. Conclusões. Referências bibliográficas. I. Marino, Francisco Paulo De Crescenzo. II. Universidade de São Paulo, Faculdade de Direito, Programa de Pós-Graduação em Direito. III. Título. 
Nome: Benedetti, Andressa

Título: Alienação fiduciária de bens imóveis em garantia aos contratos empresariais

Dissertação apresentada à Faculdade de Direito da Universidade de São Paulo, como exigência parcial para a obtenção do Título de Mestre em Direito, na área de concentração Direito Civil.

Aprovada em:

\section{Banca Examinadora}

Prof. Dr.

Instituição:

Julgamento:

Assinatura:

Prof. Dr.

Instituição:

Julgamento:

Assinatura:

Prof. Dr.

Instituição:

Julgamento:

Assinatura: 


\section{AGRADECIMENTOS}

Agradeço primeiramente a Deus, pela vida repleta de excelentes oportunidades, assim como pela saúde física e mental imprescindíveis para a conclusão de metas tão ambiciosas e desejadas, como a graduação e o mestrado na minha tão querida Faculdade de Direito da Universidade de São Paulo.

Em seguida, agradeço aos meus pais Eliana e João Luiz, que tanto me proporcionaram em termos de valores, afeto e investimento em educação e cultura, e especialmente pela confiança de que tudo é possível ser alcançado com muito esforço e dedicação. Estendo esse agradecimento a todos os meus demais familiares pelo amor, admiração e incentivo constante aos estudos.

A conclusão desse marco importantíssimo não seria possível sem o auxílio de meu orientador, Francisco Paulo De Crescenzo Marino, que apostou em meu potencial e possibilitou a realização de um grande sonho. Agradeço por todas as reuniões que me intrigaram com dezenas de inquietações e novas ideias, e pelo alto nível de exigência que me desafiou a ir além de minha zona de conforto. Agradeço também aos professores Claudio Luiz Bueno de Godoy e Juliana Krueger Pela, por terem participado de minha banca de qualificação e pelas contribuições inestimáveis ao presente trabalho.

Também serei eternamente grata a todos do Pinheiro Neto Advogados, que desde o início apoiaram esse projeto, tanto através da cultura interna que incentiva a qualidade do trabalho e o aprimoramento técnico de seus profissionais, quanto pela compreensão com a dedicação necessária aos estudos. Meu especial agradecimento aos meus mentores e exemplos, Pedro Paulo Barradas Barata, Maximilian Fierro Paschoal e Carla Cavalheiro Arantes.

Agradeço, por fim, às amigas e amigos queridos com quem tive o prazer de conviver ao longo da vida e que trouxeram leveza e alegria aos meus dias; aos professores brilhantes que contribuíram para o meu desenvolvimento acadêmico e despertaram em mim a busca pela justiça independentemente de qualquer contexto; e, por último, mas não menos importante, ao Rodrigo, com quem compartilho os próximos sonhos e a perspectiva de um futuro sempre desafiador e feliz.

São Paulo, 3 de outubro de 2018. 


\section{RESUMO}

A dissertação aborda a adequação da alienação fiduciária de bens imóveis para garantir obrigações contraídas no bojo de contratos empresariais, celebrados fora do âmbito de financiamento imobiliário-habitacional da Lei 9.514/97. Para tanto, é analisado o contexto histórico do negócio fiduciário que deu origem à alienação fiduciária em garantia, e expostas noções gerais sobre o sistema de garantias reais vigente no Brasil. Feitas tais considerações, passa-se à análise da propriedade fiduciária, expondo as suas principais vantagens, desvantagens e implicações sistêmicas. Em seguida, adentra-se no tema central do trabalho a alienação fiduciária de bens imóveis, para a compreensão do cenário legislativo no qual foi criada e das diversas modificações instituídas pelo legislador ao longo do tempo. As principais questões controvertidas referentes ao tema dizem respeito ao momento de satisfação do crédito no procedimento extrajudicial para a excussão da garantia. Após identificarmos os pontos de fragilidade da legislação quando aplicável aos contratos empresariais, propomos a integração de lacunas da Lei 9.514/97 por meio de redução teleológica para que a aplicação dos dispositivos legais esteja em consonância com a natureza da obrigação garantida, culminando na identificação de uma dualidade de regimes da propriedade fiduciária imóvel. O propósito de tal análise é oferecer ferramentas hermenêuticas ao intérprete da lei e possibilitar maior coerência sistemática e segurança jurídica na utilização da alienação fiduciária de imóveis em garantia aos contratos empresariais.

Palavras-chave: direito civil, direito empresarial, alienação fiduciária, alienação fiduciária de bens imóveis, propriedade fiduciária, garantia, contratos empresariais. 


\begin{abstract}
The paper addresses the adequacy of the fiduciary security of real-estate to guarantee obligations contracted on business agreements, apart from the real-estate financing scope of Law 9.514/97. In order to do so, we analyze the historical context of the fiduciary transaction that gave rise to the fiduciary security and we expose the general concepts regarding the legal system of real guarantees prevailing in Brazil. After these considerations, we analyze the fiduciary ownership, exposing its main advantages, disadvantages and systemic consequences. Then we go into the central theme of the paper consisting in the fiduciary security of real-estate, to understand the legislative scenario in which it was created and the several modifications instituted by legislator over time. The main controversial issues related to the subject refers to the moment of credit satisfaction by the extrajudicial proceeding to foreclose the guarantee. After identifying the weaknesses of the legislation when applicable to business agreements, we propose the integration of loopholes of Law 9.514/97 by teleological reduction to adapt the legal dispositions to the nature of the obligation guaranteed, culminating the identification of a dual system of the fiduciary ownership. The purpose of this analysis is to offer hermeneutic tools to the interpreter of the law and to allow greater systematic coherence and legal certainty regarding the use of the fiduciary security of real-estate in business agreements.
\end{abstract}

Keywords: civil law, commercial law, fiduciary security, fiduciary security of real-estate, fiduciary ownership, guarantee, business agreements. 


\section{LISTA DE SIGLAS}

$\begin{array}{ll}\text { AgRg } & \text { Agravo Regimental } \\ \text { AI } & \text { Agravo de Instrumento } \\ \text { AGU } & \text { Advocacia Geral da União } \\ \text { ARE } & \text { Agravo em Recurso Extraordinário } \\ \text { AREsp } & \text { Agravo em Recurso Especial } \\ \text { BNH } & \text { Banco Nacional de Habitação } \\ \text { CDC } & \text { Código de Defesa do Consumidor (Lei 8.078/90) } \\ \text { CRI } & \text { Certificados de Recebíveis Imobiliários } \\ \text { DJe } & \text { Diário de Justiça eletrônico } \\ \text { FGTS } & \text { Fundo de Garantia do Tempo de Serviço } \\ \text { INCRA } & \text { Instituto Nacional de Colonização e Reforma Agrária } \\ \text { RE } & \text { Recurso Extraordinário } \\ \text { REsp } & \text { Recurso Especial } \\ \text { SFH } & \text { Sistema Financeiro da Habitação } \\ \text { SFI } & \text { Sistema de Financiamento Imobiliário } \\ \text { STF } & \text { Supremo Tribunal Federal } \\ \text { STJ } & \text { Superior Tribunal de Justiça } \\ \text { TJSP } & \text { Tribunal de Justiça do Estado de São Paulo } \\ \end{array}$




\section{SUMÁRIO}

INTRODUÇÃO.

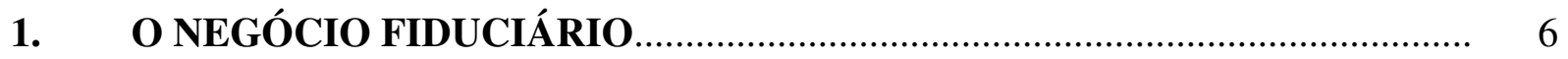

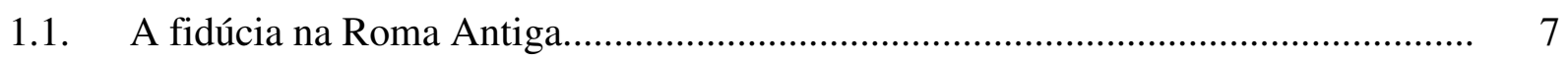

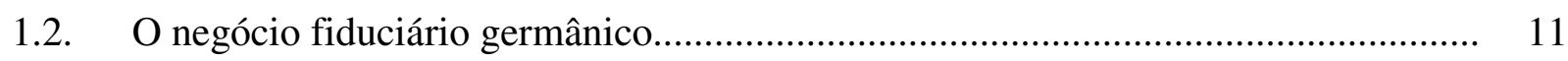

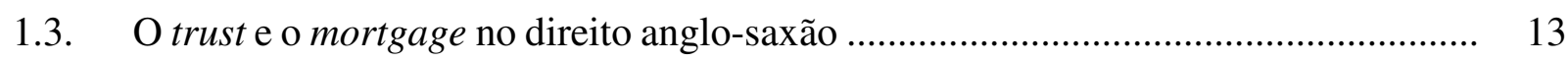

1.4. O negócio fiduciário na dogmática moderna.......................................................... 16

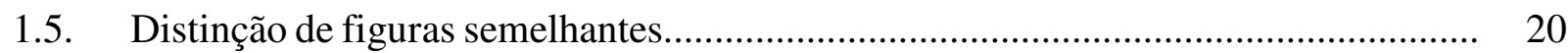

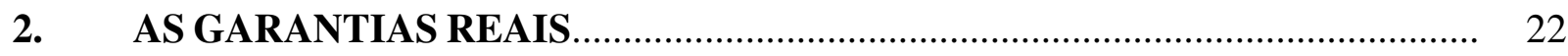

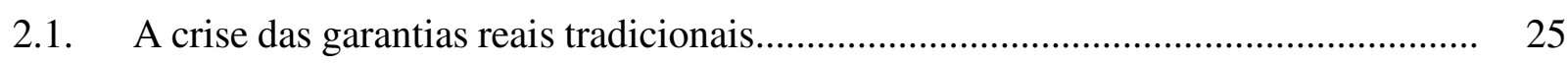

2.2. A alienação fiduciária no mercado de capitais...................................................... 28

2.3. O contrato de alienação fiduciária........................................................................ 31

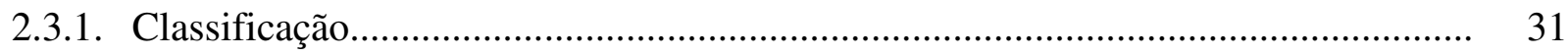

2.3.2. Requisitos de validade e fatores de eficácia.......................................................... 33

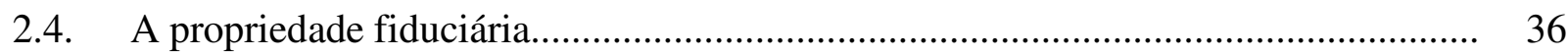

2.4.1. Pontos de contato com a propriedade resolúvel e com os direitos reais de garantia... 38

2.4.2. Os direitos decorrentes do desdobramento da posse.............................................. 40

2.4.3. A propriedade com finalidade de garantia no Direito comparado............................. 43

2.5. A supergarantia do crédito e suas implicações sistêmicas........................................ 47

3. A ALIENAÇÃO FIDUCIÁRIA DE BENS IMÓVEIS....................................... 53

3.1. O contexto prévio do SFH.............................................................................. 54

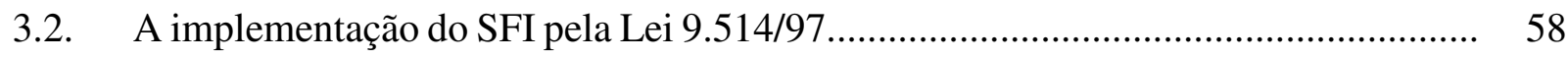

3.3. As garantias e os instrumentos aplicáveis às operações do SFI................................. 61

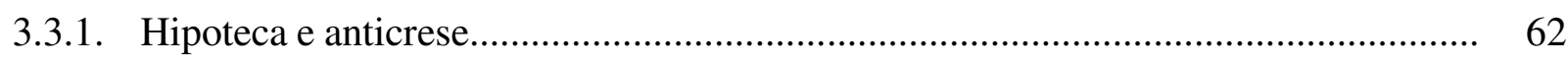

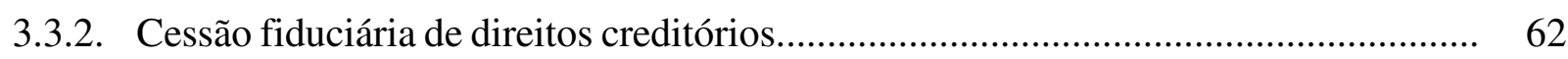

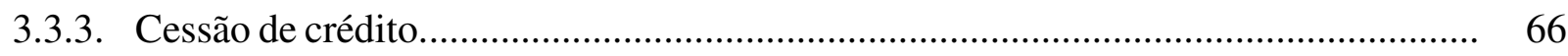




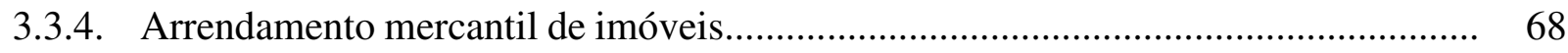

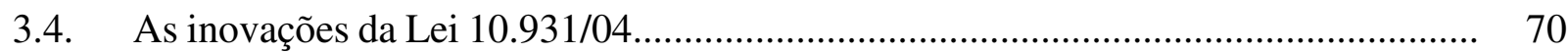

3.4.1. A extensão da alienação fiduciária de imóveis às obrigações em geral....................... 71

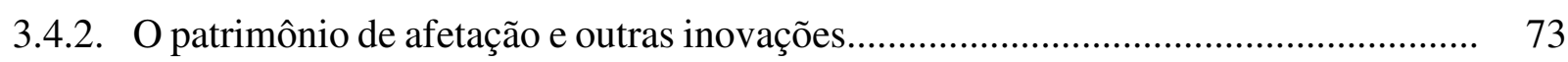

4. A SATISFAÇÃO DO CRÉDITO................................................................. 80

4.1. $\quad$ O procedimento do leilão extrajudicial................................................................... 83

4.2. As questões problemáticas decorrentes da excussão extrajudicial............................ 90

4.3. Outras restrições à satisfação do crédito............................................................... 94

4.3.1. Limitações quanto à natureza da obrigação garantida.............................................. 95

4.3.2. A alienação fiduciária de imóvel rural a credores estrangeiros................................ 100

4.3.3. O imóvel bem de família......................................................................................... 104

5. AS ADEQUAÇÕES NECESSÁRIAS AOS CONTRATOS EMPRESARIAIS. 110

5.1. A integração de lacunas por meio de redução teleológica......................................... 111

5.1.1. A aplicação de redução teleológica para integrar as lacunas da Lei 9.514/97........... 113

5.1.2. A proibição de arrematação do imóvel por preço vil................................................ 116

5.1.3. A exigibilidade da dívida remanescente............................................................... 118

5.1.4. O dever de prestar contas.................................................................................. 125

5.2. A dualidade de regimes da propriedade fiduciária imóvel..................................... 130

5.3. Alternativas possíveis aos contratos empresariais................................................ 140

5.3.1. Fracionamento da dívida e composição de garantias................................................... 141

5.3.2. Cobrança judicial da dívida............................................................................. 144

5.3.3. Celebração de pacto marciano.............................................................................. 145

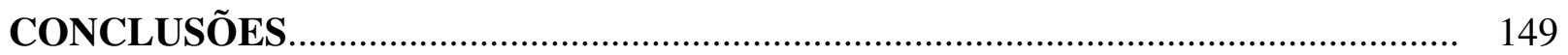

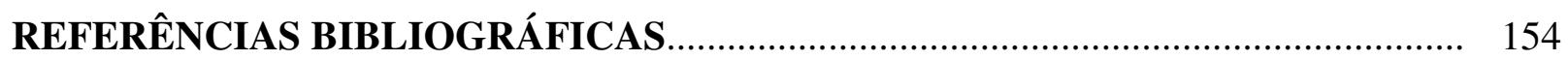




\section{INTRODUÇÃO}

A tutela do crédito é um dos pilares fundamentais da ordem econômica, por possibilitar o bom fluxo de relações entre os agentes de mercado e a realização de investimentos nos setores de comércio, indústria e serviços, com o propósito de ampliar e dinamizar a produção e o volume de negócios. Tais medidas são essenciais para gerar desenvolvimento econômico, social e nacional, um dos objetivos fundamentais da República Federativa do Brasil, conforme dispõe o art. $3^{\circ}$, inc. II, da Constituição Federal.

Os contratos bancários são, por excelência, os instrumentos relacionados à concessão de crédito. A proteção do crédito é relevante por ser uma das variáveis consideradas para a tomada de decisão, tanto no que concerne ao custo para a obtenção e concessão de crédito, quanto ao risco envolvido para a respectiva recuperação ${ }^{1}$.

A estipulação de garantias ao cumprimento das obrigações assumidas no bojo dos contratos bancários consiste em um meio adequado para mitigar o risco de crédito, reduzir os custos de transação e aumentar a eficiência econômica. Idealmente, a garantia deverá proporcionar ao credor o retorno integral do investimento de forma célere e desburocratizada ${ }^{2}$.

Com o aumento da necessidade de crédito na indústria e no comércio, sobretudo a partir da Revolução Industrial, as modalidades clássicas dos instrumentos de garantia se revelaram complexas, morosas e obsoletas frente à nova dinâmica negocial. Essa percepção

\footnotetext{
1 A Resolução 4.557/2017, do Banco Central do Brasil, dispõe acerca do gerenciamento do risco de crédito. O risco de crédito é definido pelo art. 21 como sendo a possibilidade de ocorrência de perdas associadas a: (i) não cumprimento pela contraparte de suas obrigações nos termos pactuados; (ii) desvalorização, redução de remunerações e ganhos esperados em instrumento financeiro decorrentes da deterioração da qualidade creditícia da contraparte, do interveniente ou do instrumento mitigador; (iii) reestruturação de instrumentos financeiros; ou (iv) custos de recuperação de exposições caracterizadas como ativos problemáticos.

${ }^{2}$ Otavio Yazbek pondera que a universalização do acesso do crédito é essencial para a redução dos spreads bancários, assim definidos como a "diferença entre as taxas de juros básicas (de captação) e as taxas finais (custo ao tomador)", calculados conforme as expectativas de inadimplemento para a provisão ou a reposição de perdas. Outros instrumentos negociais de administração do risco de crédito consistem na cessão de créditos, mecanismos de securitização, fundos de recebíveis, cédulas de crédito bancário, operações ativas vinculadas, derivativos de crédito e acordos de compensação. (YAZBEK, Otavio. O risco de crédito e os novos instrumentos financeiros - uma análise funcional. In: FONTES, Marcos Rolim Fernandes; WAISBERG, Ivo (coord.). Contratos Bancários. São Paulo: Quartier Latin, 2006, p. 314 e 320).
} 
se intensificou na era da tecnologia e da informação, permeada por relações complexas e dinâmicas, interligadas em rede, e em constante intercâmbio de informações e capital, nas quais o fator tempo, seja para a concessão do crédito, seja para a sua recuperação, assume grande relevância para a tomada de decisão.

Diante disso, nos últimos anos observou-se o desenvolvimento de novas espécies de garantias pessoais ${ }^{3}$, como a fiança omnibus $^{4}$, as cartas de conforto ${ }^{5}$, a garantia autônoma ${ }^{6}$, e a expansão das garantias constituídas sobre a transferência de propriedade, como a alienação fiduciária. Esta foi denominada "supergarantia"7, em razão do maior poder conferido ao credor mediante a transferência da propriedade do bem objeto da garantia, e da posição extremamente privilegiada na hipótese de inadimplemento e insolvência do devedor.

${ }^{3}$ LEITÃO, Luís Manuel Teles de Menezes. Garantia das Obrigações. $3^{\text {a }}$ ed. Coimbra: Almedina, 2012, p. 2627.

4 Também conhecida como fiança genérica. Segundo Frederico Kastrup de Faro: “apresenta-se como um subtipo da fiança de obrigações futuras a que faz referência o art. 821 do Código Civil, uma vez que, apesar de poder abranger débitos pretéritos, o diferencial da figura consiste justamente na sua habilidade para garantir créditos cujos respectivos fatos geradores só serão aperfeiçoados após a contratação da garantia." (FARO, Frederico Kastrup de. Fiança genérica (omnibus) bancária: validade e exercício da garantia à luz da boa-fé objetiva. In: GUEDES, Gisela Sampaio da Cruz; MORAES, Maria Celina Bodin de; MEIRELES, Rose Melo Vencelau; et. al. (coord.). Direito das garantias. São Paulo: Saraiva, 2017, p. 63).

5 Judith Martins-Costa e Giovana Benetti apontam que as cartas de conforto são "figuras esquivas, de conceituação fugidia, marcadas pela atipicidade" nas quais existe, "em regra, uma estrutura triangular, formada por uma sociedade mãe, autora da carta de conforto; uma sociedade filha, favorecida pelo 'conforto' assegurado pela carta; e uma instituição financeira, destinatária da carta. Muito esquematicamente: a sociedade mãe (ou controladora) dirige uma carta a um terceiro afirmando, por exemplo, que a sociedade filha (controlada, subsidiária), integra o grupo; ou então, comunica que, sendo integrante do grupo, cumprirá os seus compromissos; ou, ainda, afirma que, se a sociedade filha não os cumprir, a sociedade mãe os cumprirá." (MARTINS-COSTA, Judith; BENETTI, Giovana. As cartas de conforto: modalidades e eficácia. In: GUEDES, Gisela Sampaio da Cruz; MORAES, Maria Celina Bodin de; MEIRELES, Rose Melo Vencelau; et. al. (coord.). Direito das garantias. São Paulo: Saraiva, 2017, p. 438-441).

${ }^{6}$ A garantia autônoma, sem previsão no Direito brasileiro, tem sido utilizada no Direito europeu para impulsionar o crescimento econômico no contexto pós-guerras, por meio do desenvolvimento de mecanismo de garantia autônoma desvinculada da obrigação principal. De acordo com Luis Miguel Pestana Vasconcelos, "sendo esta garantia prestada por um banco do seu Estado, o credor afasta o risco do incumprimento ou da insolvência da outra parte, de que ele em regra tem um conhecimento escasso, contribuindo desta forma para a realização de transações que, não fosse esta garantia, não se realizariam. Por isso, se diz de forma expressiva que elas constituem 'the lifeblood of international commerce'." (VASCONCELOS, Miguel Pestana. Direito das garantias. Coimbra: Almedina, 2010, p. 121).

${ }^{7}$ Cf. Fernando Noronha: "Temos proposto que sejam designadas de supergarantias as hipóteses em que é permitido a um credor, para se assegurar do pagamento pelo devedor, assumir a propriedade da própria coisa que diz respeito à dívida, para, na hipótese de inadimplemento, poder reivindicar a restituição dessa coisa, assim ficando isento da obrigação de concorrer com quaisquer outros créditos, inclusive os detentores de créditos trabalhistas e por acidente de trabalho. Estas hipóteses, que o direito tradicional não conhecia, constituem novas formas de tutela dos interesses dos credores, sendo muito mais poderosas do que as próprias garantias reais e até do que os privilégios creditórios preferenciais." (NORONHA, Fernando. A alienação fiduciária em garantia e o leasing financeiro como supergarantias das obrigações. In: TEPEDINO, Gustavo; FACHIN, Luiz Edson. Contratos em espécie: atribuição patrimonial e garantia. São Paulo: Ed. Revista dos Tribunais, 2011, p. 740). 
Dentre as diversas modalidades de alienação fiduciária no Direito brasileiro, destaca-se aquela constituída sobre bens imóveis, introduzida pela Lei 9.514/97, que dispõe sobre o Sistema de Financiamento Imobiliário (SFI). Posteriormente, por meio do art. 51 da Lei 10.931/04, a alienação fiduciária de bens imóveis foi ampliada para garantir as obrigações em geral, com o objetivo de tutelar "o bom funcionamento do mercado de crédito brasileiro para o desenvolvimento da economia nacional" ${ }^{\text {. }}$.

A alienação fiduciária de bens imóveis passou a ser utilizada com frequência cada vez maior pelos agentes de mercado, para garantir obrigações das mais diversas naturezas. Como exemplo, pode-se citar os contratos de mútuo para a obtenção de capital de giro, os contratos de construções, os contratos de fomento mercantil (factoring), os contratos de operação de adiantamento de câmbio, os contratos de fornecimento de materiais, os contratos envolvendo empreendimentos complexos que demandam múltiplas garantias, entre outros.

O cerne do trabalho, portanto, será analisar a alienação fiduciária de bens imóveis fora do cenário legislativo no qual foi originariamente concebida, isto é, como instrumento de garantia aos contratos empresariais em sentido estrito, também denominados contratos interempresariais. Os contratos empresariais são aqueles nascidos e desenvolvidos em atividades empresariais", em que "ambas [ou todas] as partes têm no lucro o escopo de sua atividade", sendo este o fator condicionante do comportamento das partes e a função econômica do negócio ${ }^{10}$. Adotaremos, portanto, como critério distintivo dos contratos empresariais o escopo de lucro bilateral.

A análise não pretende abordar os contratos civis, celebrados entre não empresários, e os contratos de consumo ${ }^{11}$, celebrados entre um empresário e um não

\footnotetext{
${ }^{8}$ Cf. constou na Exposição de Motivos 27/2007 do Projeto de Lei 3.065/04, o qual originou a Lei 10.931/04. Disponível em: http://www.camara.gov.br/proposicoesWeb/prop_mostrarintegra?codteor=200814\& filename=PL+3065/2004. Acesso em 5 set. 2018.

${ }^{9}$ Carlos Alberto Bittar usa esse conceito para definir os contratos comerciais, que adotaremos como sinônimo aos contratos empresariais, embora o autor entenda ser de abrangência excessiva a tendência doutrinária de reconhecimento de um direito empresarial, dada a inexistência de conceito uniforme e unívoco de empresa no campo jurídico. (BITTAR, Carlos Alberto. Contratos comerciais. $5^{\mathrm{a}}$ ed. Rio de Janeiro: Forense Universitária, 2008, p. 1-2).

${ }^{10}$ FORGIONI, Paula A. Contratos Empresariais: teoria geral e aplicação. São Paulo: Editora Revista dos Tribunais, 2015, p. 34 e 40.

${ }^{11}$ Com o objetivo de distinguir os contratos empresariais dos contratos consumeristas e civis, Paula Forgioni explica que: "Nos contratos consumeristas, essa luta pelo lucro recai apenas sobre uma das partes (a empresa fornecedora); nos civis, pode inexistir (como no caso da doação) ou aparecer de forma esporádica e mitigada
} 
empresário, ou ainda entre dois ou mais empresários no qual um deles adquira produtos ou serviços para uso pessoal ou privado, na qualidade de destinatário final ${ }^{12}$. Em regra, o empresário não firmará o contrato garantido pela alienação fiduciária na qualidade de destinatário final, seja no caso de empréstimo, de financiamento ou mesmo de aquisição de bem imóvel, mas sim com o propósito de constituir, expandir ou manter sua atividade negocial ${ }^{13}$.

A depender das partes contratantes, os contratos bancários, que dão suporte à maior parte das operações garantidas por alienação fiduciária de bens imóveis, podem ser classificados como contratos empresariais ou como contratos de consumo. Não obstante, a lógica e a interpretação contratual serão totalmente diversas nessas duas hipóteses, razão pela qual entendemos não ser possível a existência de um único regime legal capaz de abarcar as especificidades de situações tão distintas.

O estudo da alienação fiduciária em garantia passa necessariamente pela análise de seu antecedente histórico, o negócio fiduciário. O primeiro capítulo do trabalho abordará as origens do negócio fiduciário, desde a sua concepção romana e as figuras afins no Direito germânico e anglo-saxão, até o resgate do seu estudo pelos pandectistas, ao final do século XIX e início do século XX.

A partir de tais substratos históricos e teóricos, no segundo capítulo do trabalho será exposto um panorama geral acerca do sistema de garantias reais no Brasil, abordando a crise das modalidades tradicionais dos direitos reais de garantia. Na sequência, trataremos do contexto no qual a alienação fiduciária em garantia foi introduzida no Direito brasileiro, através da Lei de Mercado de Capitais (Lei 4.728/65).

em um dos polos que se aproveitará economicamente do evento (locação, por exemplo). De qualquer forma, mesmo nessas hipóteses, o escopo econômico não marca o contrato de forma tão incisiva como nos casos comerciais, pois a parte não tem sua atividade profissional. O mote da empresa é diverso daquele do proprietário de um imóvel que o aluga; enquanto toda a existência da primeira justifica-se pelo fim lucrativo, o proprietário, embora deseje obter vantagem econômica do negócio, não tem nisso sua razão de ser." (Ibid., p. 40-41).

${ }^{12}$ A análise também excluirá a hipótese de aplicação do Código de Defesa do Consumidor no âmbito da teoria finalista mitigada, que admite a aplicação das normas consumeristas caso demonstrada a vulnerabilidade técnica, jurídica ou econômica da pessoa física ou jurídica que não se enquadre na definição de destinatário final.

${ }^{13}$ WALD, Arnoldo. Do regime legal da alienação fiduciária de imóveis e sua aplicabilidade em operações de financiamento de banco de desenvolvimento. Revista de Direito Imobiliário, nº 51, p. 271. 
Serão expostas, ainda, considerações referentes ao contrato de alienação fiduciária e à garantia objeto do contrato, a propriedade fiduciária. Como a utilização da propriedade com função de garantia não é uma exclusividade do Direito brasileiro, será feita uma breve exposição sobre a utilização dessa modalidade de garantia em outras ordens jurídicas. Analisaremos, em seguida, as implicações sistêmicas decorrentes da utilização da propriedade fiduciária, considerando as suas vantagens e desvantagens sob o ponto de vista das partes envolvidas na relação jurídica e da ordem econômica como um tudo.

No terceiro capítulo, trataremos sobre a alienação fiduciária de bem imóvel. Com o propósito de compreender a conjuntura na qual essa modalidade de garantia foi criada, examinaremos o panorama fático e legislativo envolvendo o Sistema Financeiro da Habitação (SFH), a sua tentativa de modernização através do SFI implementado pela Lei 9.514/97 e a expansão da alienação fiduciária de imóveis através das inovações introduzidas pela Lei 10.931/04.

No quarto capítulo, abordaremos as questões referentes à satisfação do crédito garantido através do mecanismo de excussão extrajudicial da garantia fiduciária imóvel. Nesse tema se inserem os pontos mais problemáticos com relação aos contratos empresariais, diante da incompatibilidade de diversos dispositivos da Lei 9.514/97 quando aplicados para além do SFI. Trataremos acerca de questões controversas envolvendo o leilão extrajudicial e outras restrições à alienação fiduciária de imóvel relacionadas à natureza, aos sujeitos ou ao objeto da obrigação garantida.

Por fim, no quinto capítulo, retomaremos os problemas identificados para propor a integração de lacunas da Lei 9.514/97 por meio de redução teleológica, sob a perspectiva de uma dualidade de regimes da propriedade fiduciária de bens imóveis. Também pretendese discorrer sobre os meios alternativos para evitar a aplicação literal das disposições legais e viabilizar a eficácia da garantia fiduciária imóvel no âmbito dos contratos empresariais, com o propósito de fomentar a utilização dessa modalidade de garantia e ir ao encontro das expectativas de solidez e credibilidade dos agentes econômicos. 


\section{CONCLUSÕES}

A sociedade na era da tecnologia e da informação tem se sofisticado em velocidade ímpar, permeada por relações pós-modernas hipercomplexas ${ }^{480}$ e dinâmicas interligadas em rede, na qual estão conectados empresários, instituições financeiras, investidores e consumidores, em constante intercâmbio de informações e de capital, movimentando a economia do país.

A confiança entre os agentes do mercado é de suma importância para o bom fluxo das transações comerciais, sendo imprescindível, para tanto, a existência de mecanismos de garantia sólidos e seguros para mitigar as chances de prejuízo e assegurar a recuperação do crédito. Essa demanda se intensifica no contexto atual do Brasil, permeado por crises econômicas e desemprego estrutural, no qual a incerteza e o risco crescente de inadimplemento das obrigações surgem como consequências inexoráveis.

O Direito, cumprindo a sua função de regular as expectativas e conferir durabilidade às relações sociais dinamicamente em transformação ${ }^{481}$, necessita criar mecanismos em consonância com as constantes mutações da dinâmica negocial, a fim de conferir segurança para viabilizar operações bancárias e financeiras, dirimindo o grau de incerteza quanto ao adimplemento das obrigações.

O interesse social no desenvolvimento de meios céleres para a concessão de crédito e sua posterior recuperação é comum a todas as partes. Por um lado, empresários e consumidores necessitam tomar o crédito de forma simples e desburocratizada; por outro, os investidores precisam de uma garantia robusta quanto ao cumprimento da obrigação pelo tomador do crédito, e do acesso a meios ágeis e eficientes para recuperar o crédito.

Sob o ponto de vista econômico, a segurança propiciada ao credor em face de uma garantia sólida, tal como a alienação fiduciária de bens imóveis, gera um reflexo positivo, ao aumentar a certeza quanto ao retorno dos investimentos e, consequentemente, o

\footnotetext{
${ }^{480}$ GODOY, Código Civil e Código de Defesa do Consumidor, op. cit., p. 110.

${ }^{481}$ FERRAZ JUNIOR, Tércio Sampaio. Introdução ao estudo do direito: técnica, decisão, dominação. $5^{\mathrm{a}}$ ed. São Paulo: Atlas, 2007, p. 104.
} 
volume de empréstimos concedidos. Com a diminuição da incerteza e do risco, a tendência é a queda nas taxas remuneratórias, de forma que o capital será disponibilizado no mercado a valores mais acessíveis, permitindo o crescimento econômico e o aumento na circulação de riquezas.

As modalidades clássicas dos instrumentos de garantia se mostram, muitas vezes, complexas, morosas e obsoletas frente à nova dinâmica negocial, cujo tempo para a concessão e para a recuperação do crédito é de suma relevância para a tomada de decisão, haja vista a complexa rede de relações negociais interdependentes e em constante mutação.

Apesar de a fiducia de origem romana ser mais antiga do que os direitos reais de garantia tradicionais, o estudo do negócio fiduciário somente foi resgatado ao final do século XIX e início do século XX para preencher lacunas e deficiências da legislação ${ }^{482}$. Como bem observou TUllio ASCARELli, os negócios fiduciários tendem a dar lugar a novos tipos de negócios, cujos escopos típicos são baseados nos escopos fiduciários dos negócios dos quais derivam, assumindo uma forma apropriada para tais fins ${ }^{483}$.

A alienação fiduciária consiste no negócio jurídico típico derivado do negócio fiduciário no Brasil, e foi introduzida por meio da Lei de Mercado de Capitais. A nova modalidade de garantia real foi muito bem-sucedida, diante das inúmeras vantagens proporcionadas pela transferência da propriedade ao credor, em comparação com as modalidades de garantia clássicas, como a maior celeridade para a excussão da garantia e dos benefícios legais conferidos ao credor em caso de insolvência do devedor.

Em razão do grande sucesso em sua utilização, mas sem que houvesse uma sistematização clara, coerente e didática, a alienação fiduciária teve o seu alcance progressivamente ampliado por meio de diversas legislações esparsas subsequentes editadas em contextos diversos, até abranger os bens imóveis na Lei 9.514/97.

Como referida lei foi editada para disciplinar o financiamento imobiliário no Brasil, certos dispositivos legais referentes ao procedimento para a excussão extrajudicial da garantia tinham caráter protetivo ao devedor, o qual, na maior parte dos casos, é o

${ }^{482}$ AMARAL NETO, A Alienação fiduciária em Garantia no Direito Brasileiro, op. cit., p. 320.

${ }^{483}$ ASCARELLI, Problemas das sociedades anônimas e direito comparado, op. cit., p. 106-107. 
consumidor adquirente da casa própria, vulnerável perante o credor, correspondente ao incorporador, ao construtor do imóvel, ou à instituição financeira concedente do financiamento do imóvel objeto da garantia.

A ampliação da alienação fiduciária de imóveis para garantir as obrigações em geral, trazida pelo art. 51 da Lei 10.391/04, por sua vez, não foi acompanhada da necessária reforma ou ressalva quanto à aplicação de certas normas da Lei 9.514/97, que não seriam adequadas para reger a excussão da garantia para além do SFI, sob pena de distorções.

Entre os dispositivos inadequados, chama a atenção a previsão do art. 27, §4º, $\S 5^{\circ}$ e $\S 6^{\circ}$, da Lei $9.514 / 97$. Estes parágrafos preveem que o devedor estará exonerado de pagar eventual valor remanescente da dívida após a excussão da garantia, mesmo quando o valor da garantia for insuficiente para o adimplemento total da dívida. Esta situação poderá ensejar o enriquecimento sem causa do devedor e, consequentemente, o aumento desproporcional do risco negocial.

Se, por um lado, a possibilidade de a alienação fiduciária de bens imóveis garantir contratos empresariais surgiu como uma alternativa positiva para os agentes de mercado, por outro, a falta de uma esquematização legal adequada acabou por interferir negativamente na utilização dessa nova modalidade de garantia.

A escassez de estudos sobre o tema e de decisões jurisprudenciais conflitantes motivou realizarmos por meio do presente trabalho uma reflexão acerca da aplicabilidade das normas da Lei 9.514/97, com o propósito de verificar em que medida a alienação fiduciária de imóveis é adequada para garantir obrigações contraídas por meio de contratos empresariais, que seguem lógica completamente distinta daquela do financiamento imobiliário-habitacional.

Para adequarmos a utilização da alienação fiduciária de bens imóveis à dinâmica dos contratos empresariais, submetidos a princípios basilares como a tutela da autonomia privada e da liberdade contratual e a busca por segurança e a previsibilidade, propusemos a integração das lacunas ocultas da Lei 9.514/97 por meio de redução teleológica ${ }^{484}$.

${ }^{484}$ LARENZ, Metodologia da ciência do direito, op. cit., p. 561. 
No caso da alienação fiduciária de imóveis em garantia às obrigações em geral, deverá prevalecer o princípio da responsabilidade patrimonial do devedor pelo adimplemento de suas dívidas, o dever de equidade, a cláusula geral de boa-fé objetiva, a proibição de arrematação por preço vil e a vedação ao enriquecimento sem causa de qualquer uma das partes. Tais disposições estão previstos no Código Civil e no Código de Processo Civil, cujas normas devem ser estendidas para integrar as lacunas ocultas da Lei 9.514/97.

Com efeito, o Direito pós-moderno e hipercomplexo convive com uma multiplicidade de fontes normativas que eventualmente podem conflitar ${ }^{485}$, cabendo ao intérprete obter o resultado mais razoável e que melhor corresponda às necessidades da prática para resolver a questão problemática com justiça e equidade no caso concreto ${ }^{486}$.

Considerando o tratamento diverso que a alienação fiduciária de imóveis poderá receber conforme a natureza das obrigações garantidas, e com o propósito de obter coerência sistemática e hermenêutica, identificamos uma dualidade de regimes da propriedade fiduciária imóvel: o geral, aplicável aos contratos paritários e regido pelo Código Civil e pelo Código de Processo Civil, e o especial, aplicável ao SFI, seguindo as disposições da Lei 9.514/97, mediante a interpretação finalística de cada instituto.

Concluímos que, da forma como prevista atualmente, a disciplina legal da alienação fiduciária de imóveis não é satisfatória para garantir contratos celebrados para além do SFI, como os contratos empresariais. A tipificação da alienação fiduciária em leis esparsas, motivadas por conjunturas externas diversas, como o mercado de capitais e o SFI, resultou em um regramento totalmente fragmentado e sem a sistematização necessária para proporcionar segurança jurídica.

Mesmo a previsão da propriedade fiduciária no Código Civil não foi suficiente para solucionar o problema, eis que o art. 1.361 limita a propriedade fiduciária para coisa móvel infungível, quando deveria tê-la estendido para coisas móveis e imóveis em geral, sendo os casos extraordinários regidos pela legislação específica. Ao nosso ver, a ampliação do conceito de propriedade fiduciária pelo Código Civil permitiria uma sistematização

\footnotetext{
${ }^{485}$ GODOY, Código Civil e Código de Defesa do Consumidor, op. cit., p. 110.

${ }^{486}$ MAXIMILIANO, Carlos. Hermenêutica e aplicação do direito. Rio de Janeiro: Forense, 1997, p. 165-166.
} 
adequada que traria coerência ao sistema, evitando situações iníquas.

O tratamento legal da alienação fiduciária de bens imóveis ainda é fonte de incertezas com relação ao procedimento para a excussão extrajudicial da garantia, diante do risco de aplicação indistinta dos dispositivos da Lei 9.514/97. Como os contratos de consumo e os contratos empresariais são regidos por lógicas distintas, demandam especial atenção e trabalho hermenêutico por parte do intérprete e do aplicador da lei, a evitar injustiças decorrentes da interpretação literal da lei, sem que se atente às peculiaridades do caso concreto. 


\section{REFERÊNCIAS BIBLIOGRÁFICAS}

\section{Doutrina}

ALMEIDA COSTA, Mário Júlio de. Alienação fiduciária em garantia e aquisição de casa própria (Notas de Direito Comparado). In: TEPEDINO, Gustavo; FACHIN, Edson (org.). Contratos em espécie: atribuição patrimonial e garantia. São Paulo: Ed. Revista dos Tribunais, 2011, p. 423-437.

AMARAL NETO, Francisco dos Santos. A Alienação fiduciária em Garantia no Direito Brasileiro. In: TEPEDINO, Gustavo; FACHIN, Luiz Edson. Contratos em espécie: atribuição patrimonial e garantia. São Paulo: Ed. Revista dos Tribunais, 2011, p. 315-333.

AMENDOLARA, Cesar. Alienação fiduciária como instrumento de fomento à concessão de crédito. In: FONTES, Marcos Rolim Fernandes; WAISBERG, Ivo (coord.). Contratos Bancários. São Paulo: Quartier Latin, 2006, p. 156-194.

ANDRADE, Margarida Costa. A propriedade fiduciária. In: Separata de II Seminário LusoBrasileiro de Direito Registral (Coimbra - 10 e 11 de maio de 2007). Coimbra Editora: 2009, p. 55-84.

ASCARELLI, Tullio. Problemas das sociedades anônimas e direito comparado. $2^{\mathrm{a}}$ ed. São Paulo: Saraiva, 1945.

AZEVEDO, Álvaro Villaça. Negócio Fiduciário. In: FRANÇA, Rubens Limongi (coord.). Enciclopédia Saraiva de Direito. São Paulo: Saraiva, 1977, p. 155-169, v. 54.

BALBINO FILHO, Nicolau. Registro de Imóveis. 14ª ed. São Paulo: Saraiva, 2009.

BELLOCCI, Nicla. La struttura della fiducia. Riflessiono intorno alla forma del negozio dall'epoca arcaica all'epoca classica del diritto romano. Napoli: Casa Editrice Dott. Eugenio Jovene, 1983.

BERGER, Renato. O óbvio sobre a extinção da dívida na alienação fiduciária. Revista Consultor Jurídico, 28 de novembro de 2013. Disponível em: https://www.conjur.com.br/2013-nov-28/renato-berger-obvio-extincao-divida-alienacaofiduciaria. Acesso em 8 jun. 2018.

BEZERRA FILHO, Manoel Justino. A execução extrajudicial do contrato de alienação fiduciária de bem imóvel - exame crítico da lei 9.514, de 20.11.1997. Revista dos Tribunais, v. 93 , n. 819 , jan. 2004, p. 65-76.

BIANCA, C. MASSIMO. Diritto Civile. Il Contratto. Seconda Edizione. Milano: Dott. A. Giuffrè Editore, 2000.

BIONDI, Biondo. Istituzioni di Diritto Romano. Milano: Giuffrè Editore, 1965.

BITTAR, Carlos Alberto. Contratos comerciais. $5^{\text {a }}$ ed. Rio de Janeiro: Forense 
Universitária, 2008.

BONFANTE, Pietro. Instituzioni di diritto romano. Milano: Giuffrè Editore, 1958, vol. 2.

BRANDELLI, Leonardo. Alienação fiduciária de bens imóveis. In: FARIA, Renato Vilela; CASTRO, Leonardo Freitas de Moraes e (coord.). Operações imobiliárias: Estruturação e tributação. São Paulo: Saraiva, 2016, p. 72-96.

BRESOLIN, Umberto Bara. Execução extrajudicial imobiliária: aspectos práticos. São Paulo: Atlas, 2013.

Leilão extrajudicial de imóvel objeto de alienação fiduciária em garantia: aspectos atuais e polêmicos. In: FARIA, Renato Vilela; CASTRO, Leonardo Freitas de Moraes e (coord.). Operações imobiliárias: Estruturação e tributação. São Paulo: Saraiva, 2016, p. 505-518.

BULGARELLI, Waldirio. Contratos mercantis. 14ª ed. São Paulo: Atlas, 2001.

BURDESE, Alberto. Manuale di Diritto Privato Romano. Editrice Torinese, 1964.

CAMBLER, Everaldo Augusto. Impossibilidade de registro da alienação fiduciária superveniente ou condicionada ( $2^{\circ}$ grau). In: ROCHA, Mauro Antônio; KIKUNAGA, Marcus Vinicius (org.). Alienação fiduciária de bem imóvel. 20 anos da Lei 9.514/97. Aspectos polêmicos. São Paulo: Lepanto, 2017, p. 107-124.

CARNEVALI, Ugo. Negozio giurudico. Negozio fiduciario. In: Enciclopedia Giuridica. Roma: IDEI, 1990, vol. XX.

CASTRO Y BRAVO, Federico. El negocio juridico. Madrid: Civitas, 1985.

CHALHUB, Melhim Namem. A Afetação do Acervo das Incorporações Imobiliárias. In: TUTIKIAN, Cláudia Fonseca; TIMM, Luciano Benetti; PAIVA, João Pedro Lamana. (coord). Novo Direito Imobiliário e Registral. São Paulo: Quartier Latin, $2^{\mathrm{a}}$ ed., 2008, p. 1833.

. Alienação Fiduciária: Negócio fiduciário. 5ª ed. Rio de Janeiro: Forense, 2017.

Alienação fiduciária de bens imóveis. Aspectos da formação, execução e extinção do contrato. In: DIP, Ricardo; JACOMINO, Sérgio (org.). Direito Registral. Registro imobiliário: propriedade e direitos reais limitados. São Paulo: Ed. Revista dos Tribunais, 2013, p. 787-824, vol. V.

CHALHUB, Melhim Namem; DANTZGER, Afrânio Carlos Camargo. Propriedade fiduciária: contrato de alienação fiduciária de bens imóveis e recuperação extrajudicial do crédito habitacional e empresarial. In: FARIA, Renato Vilela; CASTRO, Leonardo Freitas de Moraes e (coord.). Operações imobiliárias: Estruturação e tributação. São Paulo: Saraiva, 2016, p. 133-155.

CHRISTO, Felipe Fernandes de. Direito à quitação versus enriquecimento sem causa. Uma 
correta interpretação da Lei ${ }^{\circ}$ 9.514/97 na recuperação de créditos decorrentes de contratos de financiamento empresarial. Revista Dialética de Direito Processual, ${ }^{\circ}$ 117, p. 43-51, dez. 2012.

COELHO, Fábio Ulhôa. Comentários à Lei de falências e de recuperação de empresas. São Paulo: Revista dos Tribunais, $11^{\text {a }}$ ed., 2016.

DANTZGER, Afrânio Carlos Camargo. Alienação Fiduciária de Bens Imóveis. $2^{\mathrm{a}}$ ed. São Paulo: Método, 2007.

DAVID, René. Os grandes sistemas do direito contemporâneo. São Paulo: Martins Fontes, 1986.

DINAMARCO, Cândido Rangel. Alienação fiduciária de bens imóveis (parecer). Revista de Direito Imobiliário, ano 24, n. 51, São Paulo, p. 235-252, jul./dez., 2001.

ELIAS FILHO, Rubens Carmo. O Sistema de Financiamento Imobiliário e o Patrimônio de Afetação, para retomada do mercado imobiliário. In: FONTES, Marcos Rolim Fernandes; WAISBERG, Ivo (coord.). Contratos Bancários. São Paulo: Quartier Latin, 2006, p. 248277.

EMERICH, Yaell. Les fondements conceptuels de la fiducie face au trust de la common law: entre droit des contrats et droit des biens. Revue Internationale de Droi Comparé, n. 1, 61ème année, jan./mar., 2009.

ESPINOLA, Eduardo. Garantia e extinção das obrigações. Obrigações solidárias e indivisíveis. Campinas: Bookseller, 2005.

EUGÊNIO, Paulo Eduardo Campanella. Contornos Atuais da Alienação Fiduciária em Garantia - um Breve Ensaio sobre as Inovações Trazidas pelo Código Civil de 2002 e pela Lei 10.931/04. Revista Dialética de Direito Processual, n. 23, p. 95-111, fevereiro, 2005.

FARO, Alexandre Gereto de Mello. Notas sobre a excussão da alienação fiduciária de imóvel em garantia. São Paulo: Claris, 2016.

FARO, Frederico Kastrup de. Fiança genérica (omnibus) bancária: validade e exercício da garantia à luz da boa-fé objetiva. In: GUEDES, Gisela Sampaio da Cruz; MORAES, Maria Celina Bodin de; MEIRELES, Rose Melo Vencelau; et. al. (coord.). Direito das garantias. São Paulo: Saraiva, 2017, p. 57-122.

FERNANDES, Jean Carlos. Cessão Fiduciária de Títulos de Crédito. A posição do Credor Fiduciária no Recuperação Judicial da Empresa. Rio de Janeiro: Ed. Lumen Juris, 2009.

FERRARA, Francesco. Della Simulazione dei Negozi Giuridici. Quinta Edizione Riveduta. Roma: Athenaeum, 1922.

FERREIRA, Waldemar. O trust anglo-americano e o fideicomiso latino-americano. Revista da Faculdade de Direito da Universidade de São Paulo, n. 51, 1965. 
FOERSTER, Gerd. $O$ "trust" do direito anglo-americano e os negócios fiduciários no Brasil: perspectiva de direito comparado (considerações sobre o acolhimento do "trust" pelo Direito Brasileiro). Porto Alegre, SAFE, 2013.

FORGIONI, Paula A. Contratos Empresariais: teoria geral e aplicação. São Paulo: Editora Revista dos Tribunais, 2015.

Interpretação dos Negócios Empresariais. In: FERNANDES, WANDERLEY (coord.) Contratos Empresariais. Fundamentos e Princípios dos Contratos Empresariais. São Paulo: Saraiva, 2007, p. 75-155.

FRANCO, Luiz Henrique Sapia. Notas sobre a alienação fiduciária em garantia imobiliária: questões (ainda) controversas. Revista Forense, vol. 419, ano 110, p. 115-148, jan.-jun. 2014.

GODOY, Claudio Luiz Bueno de. Código Civil e Código de Defesa do Consumidor: convergência de princípios e distinção de sua modulação. Um paralelo entre os deveres que criam. In: MELGARÉ, Plínio (org.). O direito das obrigações na contemporaneidade: estudos em homenagem ao ministro Ruy Rosado de Aguiar Júnior. Porto Alegre: Livraria do Advogado Editora, 2014, p. 109-134.

GOMES, Orlando. Alienação fiduciária em garantia. $4^{\text {a }}$ ed. São Paulo: Ed. Revista dos Tribunais, 1975.

2008.

Direitos reais. 19a ed. Atualizada por Luiz Edson Fachin. Rio de Janeiro: Forense,

Introdução ao direito civil. $21^{\mathrm{a}}$ ed. Revista e atualizada por Edvaldo Brito e Reginalda Paranhos de Brito. Rio de Janeiro: Forense, 2016.

GONÇALVES, Aderbal da Cunha. Da propriedade resolúvel: sua projeção na alienação fiduciária em garantia. São Paulo: Revista dos Tribunais, 1979.

GUEDES, Gisela Sampaio da Cruz; TERRA, Aline de Miranda Valverde. Alienação fiduciária em garantia de bens imóveis: possíveis soluções para as deficiências e insuficiências da disciplina legal. In: GUEDES, Gisela Sampaio da Cruz; MORAES, Maria Celina Bodin de; MEIRELES, Rose Melo Vencelau; et. al. (coord.). Direito das garantias. São Paulo: Saraiva, 2017, p. 215-240.

HADDAD, Luís Gustavo. A proibição do pacto comissório no direito brasileiro. São Paulo, 2013. Tese (Doutorado em Direito Civil). Faculdade de Direito, Universidade de São Paulo.

HILL, David S. Basic Mortgage Law: cases and materials. Durham: Carolina Academic Press, 2001.

KRATOVIL, Robert. Modern Mortgage Law and Practice. Englewood Cliffs, N.J.: Prentice Hall, Inc., 1972.

LARENZ, Karl. Metodologia da ciência do direito. $3^{a}$ ed. Trad. José Lamego. Lisboa: 
Fundação Calouste Gulbenkian, 1997.

LEITÃO, Luís Manuel Teles de Menezes. Garantia das Obrigações. $3^{\mathrm{a}}$ ed. Coimbra: Almedina, 2012.

LIMA, Otto de Sousa. Negócio fiduciário. São Paulo: Ed. Revista dos Tribunais, 1962.

LIPARI, Nicolo. Il negozio fiduciario. Milano: Guiffrè, 1971.

LOTUFO, João Luís Zaratin; LOTUFO, Renan. Bem de Família no Código Civil. In: MARCACINI, Augusto Tavares Rosa et. al. Bem de Família. Aspectos Jurídicos Relevantes. São Paulo: Quartier Latin, 2012, p. 41-51.

LOUREIRO, Francisco Eduardo. Código Civil Comentado. 2ª ed. São Paulo: Manole, 2008.

LOUREIRO, José Eduardo. Alienação fiduciária de coisa imóvel. Revista do Advogado. Associação dos Advogados de São Paulo, n. 63, junho, 2001, p. 86-95.

MARINO, Francisco Paulo De Crescenzo. Contratos Coligados no Direito Brasileiro. São Paulo: Saraiva, 2009.

. Notas sobre o negócio jurídico fiduciário. Revista Trimestral de Direito Civil, v. 5, n. 20, p. 35-64, out./dez. 2004.

MARTINS, Raphael Manhães. A Propriedade Fiduciária no Direito Brasileiro: uma Proposta para a Construção Dogmática do Modelo. Revista Síntese de Direito Imobiliário, v. 01, n. 02, p. 102-115, mar./abr., 2011.

MARTINS-COSTA, Judith. Os negócios fiduciários. Consideração sobre a possibilidade de acolhimento do "trust" no direito brasileiro. Revista dos Tribunais, v. 657, p. 37-50, julho 1990.

MARTINS-COSTA, Judith; BENETTI, Giovana. As cartas de conforto: modalidades e eficácia. In: GUEDES, Gisela Sampaio da Cruz; MORAES, Maria Celina Bodin de; MEIRELES, Rose Melo Vencelau; et. al. (coord.). Direito das garantias. São Paulo: Saraiva, 2017, p. 433-463.

MARQUES, Cláudia Lima. Contratos no Código de Defesa do Consumidor. O novo regime das relações contratuais. $6^{a}$ ed. rev., atual. e ampl. São Paulo: Editora Revista dos Tribunais, 2011.

MAXIMILIANO, Carlos. Hermenêutica e aplicação do direito. Rio de Janeiro: Forense, 1997.

MESSINA, Giuseppe. Scritti Giuridici: I Negozi Fiduciari. Milano: Giuffrè, 1948.

MEZZARI, Mario Pazutti. Alienação Fiduciária da Lei n. 9.514, de 20-11-1997. São Paulo: Saraiva, 1998. 
MONTEIRO, Washington de Barros; MALUF, Carlos Alberto Dabus. Curso de direito civil. $40^{a}$ ed. São Paulo: Saraiva, 2010, vol. 3.

MONTEIRO FILHO, Carlos Edison do Rêgo. Pacto comissório e pacto marciano no sistema brasileiro de garantias. Rio de Janeiro: Processo, 2017.

MOREIRA ALVES, José Carlos. Da alienação fiduciária em garantia. $2^{\text {a }}$ ed. Rio de Janeiro: Forense, 1979.

Da fidúcia romana à alienação fiduciária em garantia no direito brasileiro. In: CAHALI, Yussef Said (coord.). Contratos nominados: São Paulo: Saraiva, 1995, p. 23-30.

Direito Romano. 13 ${ }^{\mathrm{a}}$ ed. Rio de Janeiro: Forense, 2001.

NEVES, Daniel Amorim Assumpção. Manual de Direito Processual Civil. Rio de Janeiro: Forense, 2014.

NORONHA, Fernando. A alienação fiduciária em garantia e o leasing financeiro como supergarantias das obrigações. In: TEPEDINO, Gustavo; FACHIN, Luiz Edson (org.). Contratos em espécie: atribuição patrimonial e garantia. São Paulo: Ed. Revista dos Tribunais, 2011, p. 739-756.

PANTANO, Tânia. Execução extrajudicial de alienação fiduciária de imóvel. In: FARIA, Renato Vilela; CASTRO, Leonardo Freitas de Moraes e (coord.). Operações imobiliárias: Estruturação e tributação. São Paulo: Saraiva, 2016, p. 199-211.

PENTEADO, Luciano de Camargo. Direito da Coisas. São Paulo: Revista dos Tribunais, 2008.

PEREIRA, Caio Mario da Silva. Instituições de Direito Civil. Contratos. Declaração unilateral de vontade. Responsabilidade civil. 19ª ed. Rio de Janeiro: Forense, 2015.

Instituições de Direito Civil. Direitos Reais. Posse. Propriedade. Direitos reais de fruição, Garantia e Aquisição. 23 ${ }^{\mathrm{a}}$ ed. Rio de Janeiro: Forense, 2015.

PERES, Tatiana Bonatti; JABUR, Rentato Pinheiro. Alienação fiduciária em garantia de bens imóveis e a quitação sem pagamento prevista nos $\S \S 5^{\circ}$ e $6^{\circ}$ do artigo 27 da Lei 9.514/97. In: PERES, Tatiana Bonatti; FAVACHO, Frederico. Agronegócio. São Paulo: Chiado Editora, 2017, p. 147-174, vol. 2.

PONTES DE MIRANDA, Francisco Cavalcanti. Tratado de Direito Privado: Parte Especial. Direito das coisas: Direitos reais de garantia. Hipoteca. Penhor. Anticrese. Atualizado por Vilson Rodrigues Alves. $1^{a}$ ed. São Paulo: Bookseller, 2002, Tomo XX.

Tratado de Direito Privado: Parte Especial. Direito das coisas: Penhor Rural. Penhor Industrial. Penhor mercantil. Anticrese. Cédulas rurais pignoratícias, hipotecárias e mistas. Transmissões em garantia. Atualizado por Nelson Nery Jr. et. at. São Paulo: Editora Revista dos Tribunais, 2012, Tomo XXI. 
Tratado de Direito Privado: Parte Especial. Direito das obrigações: Autoregramento da vontade e lei. Alteração das relações jurídicas obrigacionais. Transferência de créditos. Assunção de dívida alheia. Transferência da posição subjetiva nos negócios jurídicos. Atualizado por Nelson Nery Jr. et. at. São Paulo: Editora Revista dos Tribunais, 2012, Tomo XXIII.

PRADO, Marcos Lopes. Eventual não extinção legal da dívida garantida por meio de alienação fiduciária de imóvel, em caso de segundo leilão negativo. In: ROCHA, Mauro Antônio; KIKUNAGA, Marcus Vinicius (org.). Alienação fiduciária de bem imóvel. 20 anos da Lei 9.514/97. Aspectos polêmicos. São Paulo: Lepanto, 2017, p. 237-258.

RESTIFFE, Paulo Sergio; RESTIFFE NETO, Paulo. Propriedade fiduciária imóvel: nas modalidades de financiamento mercadológico e autofinanciamento consorcial e transmissão dos novos direitos fiduciários e seus reflexos na recuperação judicial ou falência. São Paulo, Malheiros, 2009.

RESTIFFE NETO, Paulo. Garantia fiduciária: direito e ações: Manual teórico e prático com jurisprudência. São Paulo, Ed. Revista dos Tribunais, 1976.

ROCHA, Mauro Antônio. (Im)possibilidade de registro imobiliário da alienação fiduciária condicionada ou superveniente $-2^{\circ}$ grau. In: ROCHA, Mauro Antônio; KIKUNAGA, Marcus Vinicius (org.). Alienação fiduciária de bem imóvel. 20 anos da Lei 9.514/97. Aspectos polêmicos. São Paulo: Lepanto, 2017, p. 125-147.

SALOMÃO NETO, Eduardo. O Trust $e$ o direito brasileiro. São Paulo: LTr, 1996.

SANTOS, José Beleza dos. A simulação em direito civil. 2a ed. São Paulo: Lejus, 1999.

SILVA, Fábio Rocha Pinto e. Garantias imobiliárias em contratos empresariais: hipoteca e alienação fiduciária. São Paulo: Almedina, 2014.

. Não exoneração da responsabilidade pessoal do devedor na excussão da alienação fiduciária de imóveis. In: ROCHA, Mauro Antônio; KIKUNAGA, Marcus Vinicius. Alienação fiduciária de bem imóvel. 20 anos da Lei 9.514/97. Aspectos polêmicos. São Paulo: Lepanto, 2017, p. 213-236.

STALDER, Marc. (Im)possibilidade de registro imobiliário da alienação fiduciária em garantia condicionada ou superveniente. In: ROCHA, Mauro Antônio; KIKUNAGA, Marcus Vinicius (org.). Alienação fiduciária de bem imóvel. 20 anos da Lei 9.514/97. Aspectos polêmicos. São Paulo: Lepanto, 2017, p. 81-105.

TEPEDINO, Gustavo. Comentários ao código civil: direito das coisas (Arts. 1.196 a 1.276). São Paulo: Saraiva, 2011, Tomo 14.

TEPEDINO, Gustavo; GONÇALVES, Marcos Alberto Rocha. Lições da VII jornada de direito civil: tendências do direito das coisas. Conjur. Disponível em: https://www.conjur.com.br/2016-fev-08/direito-civil-atual-licoes-vii-jornada-direito-civiltendencias-direito-coisas. Acesso em 2 jun. 2018. 
TERRA, Marcelo. Alienação Fiduciária de Imóvel em Garantia. Porto Alegre: Sérgio Antonio Fabris, 1998.

VASCONCELOS, Luis Miguel Pestana. Direito das garantias. Coimbra: Almedina, 2010.

VASCONCELOS, Pedro Pais de. Contratos Atípicos. 2a ed. Coimbra: Almedina, 2009.

YAZBEK, Otavio. O risco de crédito e os novos instrumentos financeiros - uma análise funcional. In: FONTES, Marcos Rolim Fernandes; WAISBERG, Ivo (coord.). Contratos Bancários. São Paulo: Quartier Latin, 2006, p. 310-337.

WALD, Arnoldo. A alienação fiduciária de imóveis. Revista de Direito Bancário e do Mercado de Capitais. Ed. Revista dos Tribunais, ano 1, n. 2, mai./ago., 1998.

Alguns aspectos do regime jurídico do Sistema Financeiro Imobiliário (Lei 9.514/97). Revista de Direito Bancário e do Mercado de Capitais. Ed. Revista dos Tribunais, ano 2, n. 4, p. 13-27, jan.-abr., 1999.

. Da Alienação Fiduciária. Revista Forense, v. 227, p. 377-381, jul./set., 1969.

Da licitude da promessa de venda de coisa alheia. In: NERY JUNIOR, Nelson; NERY, Rosa Maria de Andrade (org.). Responsabilidade civil. Direito de obrigações e Direito Negocial. São Paulo: Ed. Revista dos Tribunais, vol. II, p. 931-952, 2010.

Do regime legal da alienação fiduciária de imóveis e sua aplicabilidade em operações de financiamento de banco de desenvolvimento. Revista de Direito Imobiliário, $\mathrm{n}^{\text {o }} 51$, p. $253-279$.

\section{Jurisprudência}

\section{STF}

Superior Tribunal Federal, Recurso Extraordinário 68966/SP, 2a Turma, Relator Ministro Thompson Flores, julgado em 25 set. 1970.

Superior Tribunal Federal, Recurso Extraordinário 71616/SP, $1^{a}$ Turma, Relator Ministro Rodrigues Alckmin, julgado em 11 dez. 1973.

Superior Tribunal Federal, Habeas Corpus 72131/RJ, Tribunal Pleno, Relator Ministro Marco Aurélio, julgado em 23 nov. 1995.

Superior Tribunal Federal, Recurso Extraordinário 206086/SP, 1ª Turma, Relator Ministro Ilmar Galvão, julgado em 12 nov. 1996.

Superior Tribunal Federal, Repercussão Geral no Recurso Extraordinário 928902 RG/SP, Tribunal Pleno, Relator Ministro Dias Toffoli, julgado em 17 out. 2018. 


\section{STJ}

Superior Tribunal de Justiça, Recurso Especial 16242/SP, 4ª Turma, Relator Ministro Sálvio de Figueiredo Teixeira, julgado em 31 ago. 1992.

Superior Tribunal de Justiça, Recurso Especial 78.022/PR, 2a Turma, Relator Ministro Peçanha Martins, julgado em 6 mar. 1997.

Superior Tribunal de Justiça, Recurso Especial 138421/RJ, $4^{\text {a }}$ Turma, Relator Ministro Ruy Rosado de Aguiar, julgado em 10 nov. 1997.

Superior Tribunal de Justiça, Recurso Especial 162.942/MS, 4 ${ }^{\text {a }}$ Turma, Relator Ministro Sálvio de Figueiredo Teixeira, julgado em 30 abr. 1998.

Superior Tribunal de Justiça, Embargos de Divergência em Recurso Especial 149.518/GO, Corte Especial, Relator Ministro Ruy Rosado de Aguiar, julgado em 5 mai. 1999.

Superior Tribunal de Justiça, Recurso Especial 655.471/MG, $3^{\mathrm{a}}$ Turma, Relator Ministro Carlos Alberto Menezes Direito, julgado em 15 set. 2005.

Superior Tribunal de Justiça, Recurso Especial 827.085/SP, $4^{\mathrm{a}}$ Turma, Relator Ministro Jorge Scartezzini, julgado em 4 mai. 2006.

Superior Tribunal de Justiça, Recurso Especial 1006387/SC, $3^{\text {a }}$ Turma, Relatora Ministra Nancy Andrighi, julgado em 2 set. 2010.

Superior Tribunal de Justiça, Conflito de Competência 110.392/SP, 2ª Seção, Relator Ministro Raul Araújo, julgado em 24 nov. 2010.

Superior Tribunal de Justiça, Recurso Especial 1328656/GO, $4^{\text {a }}$ Turma, Relator Ministro Marco Buzzi, julgado em 18 set. 2012.

Superior Tribunal de Justiça, Recurso Especial 1.202.918/SP, $3^{\mathrm{a}}$ Turma, Relator Ministro Ricardo Villas Bôas Cueva, julgado em 7 mar. 2013.

Superior Tribunal de Justiça, Recurso Especial 1101375/RS, $4^{\text {a }}$ Turma, Relator Ministro Luis Felipe Salomão, julgado em 4 jun. 2013.

Superior Tribunal de Justiça, Recurso Especial 1395275/MG, $4^{\text {a }}$ Turma, Relator Ministro Luis Felipe Salomão, julgado em 22 abr. 2014.

Superior Tribunal de Justiça, Recurso Especial 1462210/RS, $3^{\text {a }}$ Turma, Relator Ministro Ricardo Villas Bôas Cueva, julgado em 18 nov. 2014.

Superior Tribunal de Justiça, Agravo Regimental no Agravo Regimental no Recurso Especial 1.172.146/SP, 4 $4^{\mathrm{a}}$ Turma, Rel. Min. Antônio Carlos Ferreira, julgado em 18 jun. 2015.

Superior Tribunal de Justiça, Recurso Especial 1542275/MS, $3^{\text {a }}$ Turma, Relator Ministro 
Ricardo Villas Bôas Cueva, julgado em 24 nov. 2015.

Superior Tribunal de Justiça, Agravo Regimental no Recurso Especial 1204310/RS, $4^{\text {a }}$ Turma, Relator Ministro Raul Araújo, julgado em 14 fev. 2017.

Superior Tribunal de Justiça, Recurso Especial 1622555/MG, 2a Seção, Relator Ministro Marco Buzzi, julgado em 22 fev. 2017.

Superior Tribunal de Justiça, Agravo Interno no Agravo Regimental no Agravo em Recurso Especial 772.722/PR, $4^{\mathrm{a}}$ Turma, Relatora Ministra Maria Isabel Galotti, julgado em 18 abr. 2017.

Superior Tribunal de Justiça, Recurso Especial 1446249/SP, $2^{\text {a }}$ Turma, Relator Ministro Og Fernandes, julgado em 21 set. 2017.

Superior Tribunal de Justiça, Agravo Interno nos Embargos de Declaração no Agravo em Recurso Especial 975.829/SE, $4^{\text {a }}$ Turma, Relatora Ministra Maria Isabel Galotti, julgado em 3 out. 2017.

Superior Tribunal de Justiça, Recurso Especial 1678525/SP, 4a Turma, Relator Ministro Antonio Carlos Ferreira, julgado em 5 out. 2017.

Superior Tribunal de Justiça, Agravo Interno no Agravo em Recurso Especial 109523/DF, 4 ${ }^{\mathrm{a}}$ Turma, Relatora Ministra Maria Isabel Galotti, julgado em 28 nov. 2017.

Superior Tribunal de Justiça, Recurso Especial 1646249/RO, 2a Turma, Relator Ministro Herman Benjamin, julgado em 3 abr. 2018.

Superior Tribunal de Justiça, Recurso Especial 1697645/MG, $2^{\text {a }}$ Turma, Relator Ministro Og Fernandes, julgado em 19 abr. 2018.

Superior Tribunal de Justiça, Embargos de Divergência em Agravo em Recurso Especial 848.498/PR, 2a Seção, Relator Ministro Luis Felipe Salomão, julgado em 25 abr. 2018.

Superior Tribunal de Justiça, Recurso Especial 1677015/SP, $3^{\text {a }}$ Turma, Relator Ministro Paulo de Tarso Sanseverino, Relatora para acórdão Ministra Nancy Andrighi, julgado em 28 ago. 2018.

Superior Tribunal de Justiça, Recurso Especial 1696038/SP, $3^{\text {a }}$ Turma, Relator Ministro Ricardo Villas Bôas Cueva, julgado em 3 set. 2018.

Superior Tribunal de Justiça, Recurso Especial 1677079/SP, $3^{\text {a }}$ Turma, Relator Ministro Ricardo Villas Bôas Cueva, julgado em 25 set. 2018.

Superior Tribunal de Justiça, Recurso Especial 1155547/MG, $4^{\mathrm{a}}$ Turma, Relator Ministro Marco Buzzi, julgado em 6 nov. 2018. 


\section{TJSP}

Tribunal de Justiça do Estado de São Paulo, Apelação Com Revisão 904484975.1998.8.26.0000, $11^{\mathrm{a}}$ Câmara (Extinto $1^{\circ} \mathrm{TAC}$ ), Desembargador Relator Silveira Paulilo, julgado em 28 jun. 2001.

Tribunal de Justiça do Estado de São Paulo, Apelação Cível 580-6/8, Corregedoria Geral de Justiça do Estado de São Paulo, Desembargador Relator Gilberto Passos de Freitas, julgado em 19 abr. 2007.

Tribunal de Justiça do Estado de São Paulo, Apelação Cível 1.120.758-0/02, 36 Câmara de Direito Privado, Desembargador Relator Romeu Ricupero, julgado em 31 jan. 2008.

Tribunal de Justiça do Estado de São Paulo, Agravo de Instrumento 1246070005, 28 a Câmara de Direito Privado, Desembargador Relator Eduardo Sá Pinto Sandeville, julgado em 16 jun. 2009.

Tribunal de Justiça do Estado de São Paulo, Apelação 9103689-29.2008.8.26.0000, 4 ${ }^{\text {a }}$ Câmara de Direito Privado, Desembargador Relator Enio Zuliani, julgado em 27 ago. 2009.

Tribunal de Justiça do Estado de São Paulo, Agravo de Instrumento 031532848.2010.8.26.0000, $13^{\mathrm{a}}$ Câmara de Direito Privado, Desembargador Relator Ulisses do Vale Ramos, julgado em 26 ago. 2010.

Tribunal de Justiça do Estado de São Paulo, Mandado de Segurança 005894733.2012.8.26.0000, Órgão Especial, Desembargador Relator Guerrieri Rezende, julgado em 12 set. 2012.

Tribunal de Justiça do Estado de São Paulo, Apelação 0158705-15.2008.8.26.0100, 25a Câmara de Direito Privado, Desembargador Relator Vanderci Álvares, julgado em 29 ago. 2013.

Tribunal de Justiça do Estado de São Paulo, Agravo de Instrumento 205944731.2013.8.26.0000; $24^{\mathrm{a}}$ Câmara de Direito Privado; Desembargador Relator Plinio Novaes de Andrade Júnior, julgado em 27 mar. 2014.

Tribunal de Justiça do Estado de São Paulo, Agravo de Instrumento 202876996.2014.8.26.0000, 33 ${ }^{\mathrm{a}}$ Câmara de Direito Privado, Desembargadora Relatora Maria Cláudia Bedotti, julgado em 12 mai. 2014.

Tribunal de Justiça do Estado de São Paulo, Apelação 0039357-75.2009.8.26.0000, 32º Câmara de Direito Privado, Desembargador Relator Kioitsi Chicuta, julgado em 22 jan. 2015.

Tribunal de Justiça do Estado de São Paulo, Agravo de Instrumento 203409333.2015.8.26.0000, $1^{\text {a }}$ Câmara Reservada de Direito Empresarial, Desembargador Relator Francisco Loureiro, julgado em 8 abr. 2015.

Tribunal de Justiça do Estado de São Paulo, Apelação 0013993-20.2011.8.26.0554, 36 
Câmara de Direito Privado, Desembargador Relator Walter Cesar Exner, julgado em 10 dez. 2015.

Tribunal de Justiça do Estado de São Paulo, Apelação 1002050-35.2015.8.26.0073, Conselho Superior de Magistratura, Desembargador Relator Pereira Calças, julgado em 2 jun. 2016.

Tribunal de Justiça do Estado de São Paulo, Apelação 0004901-48.2014.8.26.0025, 13a Câmara de Direito Privado, Desembargador Relator Francisco Giaquinto, julgado em 17 ago. 2016.

Tribunal de Justiça do Estado de São Paulo, Apelação 1046052-43.2014.8.26.0100, 29a Câmara de Direito Privado, Desembargadora Relatora Silvia Rocha, julgado em 8 fev. 2017.

Tribunal de Justiça do Estado de São Paulo, Apelação 1007816-77.2014.8.26.0405, 27 Câmara Extraordinária de Direito Privado, Desembargador Relator Marcos Ramos, julgado em 16 out. 2017.

Tribunal de Justiça do Estado de São Paulo, Apelação 1011113-47.2015.8.26.0344, 32a Câmara de Direito Privado, Desembargador Relator Caio Marcelo Mendes de Oliveira, julgado em 19 out. 2017.

Tribunal de Justiça do Estado de São Paulo, Apelação 1017476-98.2017.8.26.0564, 22a Câmara de Direito Privado, Desembargador Relator Hélio Nogueira, julgado em 26 abr. 2018.

Tribunal de Justiça do Estado de São Paulo, Apelação 1127928-83.2015.8.26.0100, 12a Câmara de Direito Privado, Desembargador Relator Tasso Duarte de Melo, julgado em 21 mai. 2018.

Tribunal de Justiça do Estado de São Paulo, Agravo de Instrumento 225094313.2017.8.26.0000, 33 $3^{\mathrm{a}}$ Câmara de Direito Privado, Desembargador Relator Luiz Eurico, julgado em 11 jun. 2018. 